\title{
Towards a model of normative diagnosis in the organizational context: The evaluative model of normative appeals
}

\author{
Sergio Salgado ${ }^{1}$ (D) Luis Oceja ${ }^{2}$ (iD), Maite Beramendi ${ }^{3}$ (D), Carolina González ${ }^{1}$ \\ ${ }^{1}$ Universidad de La Frontera (Chile) \\ ${ }^{2}$ Universidad Autónoma de Madrid (Spain) \\ ${ }^{3}$ Universidad de Buenos Aires-CONICET (Argentina) \\ sergio.salgado@ufrontera.cl,hiis.ocej@@uam.es,maiteberamendi@gmail.com,carolina.gonzalez@ufrontera.cl
}

Received November, 2017

Accepted April, 2018

\section{Abstract}

Purpose: The aim of the present work is to advance in a topic that has received little attention in the literature: normative diagnosis; contributing new empirical evidence to a recently proposed model: The Evaluative Model of Normative Appeals (EMNA).

Design/methodology: Two field studies were carried out. In Study 1 we tested the EMNA premises by appraising a normative appeal in a university organizational context $(N=304)$. In Study 2, we contributed to the predictive validity of the model by analyzing the perception and adherence with two normative appeals in the context of labor organizations $(N=296)$.

Findings: The results of both studies supported the premises of the EMNA and its potential as a normative diagnostic tool for the organizational context.

Research limitations/implications: The EMNA should be analyzed in relation to other models in order to complement its explanatory and diagnostic value. The results obtained and the validity of the scales should be tested in new samples from different countries.

Practical implications: From an applied point of view, the EMNA represents a tool to support the diagnosis and management of organizational normative appeals in at least two situations: in establishing predictions regarding levels of adherence or willingness to comply, and in monitoring the effectiveness of the measures that have been adopted to modify the perception of certain regulations.

Social implications: The transgression of the rules generates large direct (e.g., money laundering, corruption) and indirect losses (e.g., loss of prestige, dysfunctional behavior), so achieving more efficient regulatory management is a constant challenge, both socially and organizationally. The present work represents an advance in the challenge of reducing the levels of transgression and its associated costs.

Originality/value: The present work provides complementary evidence that supports the utility of a recently proposed model, as a tool for normative diagnosis in the organizational field.

Keywords: Normative diagnosis, Compliance management, Formality, Protection, Organizational norms

Jel Codes: M10, M12, M48, M54, D23, L20 


\section{Introduction}

Regulatory transgression generates large direct (e.g., money laundering, corruption) and indirect problems (e.g., loss of prestige, dysfunctional behaviors), so achieving more efficient normative management is a constant challenge, on both a social and an organizational level (e.g., Burke \& Cooper, 2009). Governments, for example, require the meeting of a growing demand for social rights. To achieve this, it is essential boost compliance with a series of regulations, which range from fiscal and tax laws to policies and rules that ensure the good use of public resources. Furthermore, the success of organizations depends to a large extent on their members following as closely as possible the set of norms (i.e., laws, regulations, policies, codes of ethics, etc.) that have been established to ensure proper operation. However, despite the considerable resources invested by both institutions and organizations, the transgression of regulations is a constant problem (e.g., Boda \& Zsolnai, 2016; Detert, Trevino, Burris \& Andiappan, 2007; Greve, Palmer \& Pozner, 2010; Healy \& Iles, 2002).

Therefore, it is necessary to expand the field of knowledge that Morris and his colleagues have referred to as Normology, namely., the study of norms (Morris, Hong, Chiu \& Liu, 2015). Within this field, the present work considers a topic that has received little attention in the literature: normative diagnosis. Specifically, we contribute new empirical evidence to a recently proposed model: The Evaluative Model of Normative Appeals (EMNA) (Oceja, Villegas, Beramendi \& Salgado, 2016).

Two studies were carried out. In the first, the premises of the EMNA were tested by appraising a normative appeal in a university organizational context $(N=304)$. In the second, the predictive validity of the model was further tested by analyzing the perception and adherence with two normative appeals in the context of labor organization $(N=296)$. The results of both studies support the EMNA premises and its potential as a normative diagnostic tool.

Perception of the norms and adherence. From the field of Social and Organizational Psychology, the perception of norms and their effect on adherence has been approached from different perspectives. On one side, there is the influence of Dissuasion Theory, which is based on the Rational Choice Theory (Andenaes, 1974; Beccaria, 1764/2011; Becker, 2004; Cornish \& Clarke, 2013). This explanation of normative compliance assumes that people are rational, dominate their actions at their will and that the decision-making process is based on the analysis of the costs and benefits associated with the compliance with or the transgression of the norms. As a result, normative management based on a rational dissuasive focus emphasizes the use of control and sanctions to increase the level of adherence, and its usefulness has been analyzed on both a social (e.g., Nagin \& Paternoster, 1991; Paternoster \& Bachman, 2013) and an organizational level (e.g., Cheng, Li, Li, Holm \& Zhai, 2013; Cheng, Li, Zhai \& Smyth, 2014). This focus, however, is not free of criticism. On the one hand, it has been acknowledged that rationalistic normative management requires the investment of an important amount of human and economic resources, which make it possible to effectively control and apply the established punitive measures (Tyler \& Blader, 2005). In addition, these resources are not always considered to be good investments, due to their limited effectiveness as deterrents of the transgression or promoters of a greater level of adherence (e.g., Katyal, 1997; Llinares \& Ortuño, 2013; MacCoun, 1993; Markell, 2000; Sutinen \& Kuperan, 1999; Tyler \& Huo, 2002).

From a different point of view, we find research on social influence (Cialdini \& Goldstein, 2004; Harkins, Williams \& Burger, 2017). From this perspective, one of the foremost works is that by Cialdini and his colleagues: A Focus Theory of Normative Conduct (FTNC; Cialdini, 2012; Cialdini, Kallgren \& Reno, 1991; Cialdini, Reno \& Kallgren, 1990). According to the FTNC, a norm affects our behavior when is within our focus of attention at the time of the decision (i.e., salience; Kallgren, Reno \& Cialdini, 2000), along with two additional factors: our belief in what the reference group expects us to do (i.e., injunctive norms) and what we perceive as the generalized mode of conduct (i.e., descriptive norm; Reno, Cialdini \& Kallgren, 1993). While this process can explain a good share of the influence of social norms on conduct, it leaves some important questions unanswered. For example, what happens when we observe that most people obey a norm or we feel that the group expects this norm to be obeyed, but we do not agree with what the norm requires? 
One way of dealing with the limitations offered by Dissuasion Theory and FTNC is to consider a complementary concept: legitimacy. Among the approaches that address it, the Relational Model of Authority (Tyler, 2006; Tyler \& Lind, 1992) establishes that the probability that a norm will be obeyed depends on the level of legitimacy of the authority establishing it, which in turn depends on whether the exercise of its authority is perceived as just. It has been demonstrated that the legitimacy of authority is related to higher levels of commitment and different forms of organizational cooperation, such as greater adherence to the norms and the making of extra-role efforts in favor of the smooth operation of the organization (Tyler \& Blader, 2000). However, the Relational Model of Authority does not completely explain the relationship between the authority figure and the norms that it tries to establish. For example, can people negatively assess the imposition of a norm that comes from an authority that is perceived as legitimate?

Another antecedent of normative compliance related to the concept of legitimacy refers to the level of affinity or coherence between the activity of the organization and that which is considered to be correct. In the literature, at least two types of assessment have been suggested in this regard: one more sociocentric, in which the assessment of congruence takes place between the culture and behavior of the organization, and what is understood as good or necessary on a social level (Dowling \& Pfeffer, 1975; Pfeffer, 1981; Pfeffer \& Salancik, 1978; Suchman, 1995); and another more anthropocentric, in which the assessment of congruence takes place between what is expressed by the organization or its representatives and personal values and beliefs. This latter perspective is associated with concepts such as moral value congruence (Tyler \& Blader, 2005) and the personorganization fit (Edwards \& Cable, 2009). The literature presents evidence showing the relationship between value congruence and normative compliance (e.g., Son, 2011; Tyler \& Blader, 2005); however, taking this perspective is difficult to determine what personal values are central and/or will be situationally activated (Verplanken \& Holland, 2002) when evaluating a specific norm; it therefore proves difficult to predict the result of this assessment at any given moment.

Based on the analysis of these limitations, Oceja and his colleagues (2016) developed the Evaluative Model of Normative Appeals. The EMNA has two fundamental premises. Firstly, the perception of a normative appeal is structured according to a two-dimensional normative appraisal: the degree to which the individual perceives that the appeal comes from a formal institution that backs it and ensures its compliance (i.e., formality) and the degree to which the person perceives that the appeal either prevents harm or promotes the performance of the action, or both (i.e., protection). From this two-dimensional normative appraisal, a classification can be established consisting of four basic categories (see Figure 1): legitimate (high in protection and high in formality), prescription (high in protection and low in formality), coercive (low in protection and high in formality) and use (low in protection and low in formality). It is important to point out that the EMNA does not suggest that the individual directly perceives a specific normative appeal as one of these categories, rather that the perception of the level of formality and protection of said appeal can later be classified (by researchers) into one of these four basic categories.

Secondly, the authors establish that the willingness to comply is related to both formality and protection, but to a greater extent with protection due to its relationship with the self-regulatory system (Higgins, 2012). Consequently, the EMNA considers that the four normative categories are related to the willingness to comply in an ascending continuum that goes from use, to coercive, to prescriptive, to legitimate (Oceja et al., 2016). Previous research provided evidence that support the premises of the EMNA. In the first study presented by Oceja et al. (2016), the participants evaluated the level of formality and protection of 28 normative appeals. The results showed that based on this evaluation, the perception of the normative appeals can be classified into the four categories of the model: legitimate, prescription, coercive and use. The second study used a new sample to verify whether these categories showed different levels of adherence in line with the EMNA premises, and the results supported the hypothesis.

The present research. The present work complements the previous research in two aspects. First, in Oceja et al. (2016), the relationship of the model categories with the different levels of adherence was determined at an inter-subject level. In this work, this relationship was analyzed at an intra-subject level, which made it possible to directly verify the relationship between the normative appraisal proposed by the EMNA (i.e., the perception of 
formality and protection that results in four normative categories) and the level of adherence with the appeal (organized in ascending continuum that goes from use, to coercive, to prescription, to legitimate). Second, in the present work the model is applied to appraise the perception of normative appeals that affect two different organizational contexts, and to predict adherence with those.

\section{Studies}

\subsection{Study 1}

The aim of this study was to analyze the premises of the EMNA at an intra-subject level, in a university organizational context. Considering that the study would be conducted on students, a normative appeal was chosen that was related to their role as members of the university community: "The federated strike must be respected." This normative proposal establishes that, as a way to support the negotiation processes with university authorities, the stoppage of academic activities (especially classes) must be backed by the Federation of University Students. Besides, this proposal is covered in the Regulation for the Coexistence of University Students (Exempt resolution 0033 of 2009 of the university, section on Stoppage of activities, page 2), establishing that once the phases of presentation and dialog have been exhausted and "in the case no answer is received or this is unsatisfactory, the students may suspend their academic activities, which consists of the total or partial suspension of educational activities for the duration of the conflict." Therefore, objectively speaking, the "federated strike" proposal is both formal and protective. However, regarding the use of the EMNA as a normative diagnostic model, we test whether the level of adherence does not depend as much on this apparent objective character as it does on how it is actually perceived by those who are compelled to comply with it (MacCoun, 1993; Oceja et al., 2016).

Hypothesis. We hypothesize that, according to the appraisal proposed by the EMNA, the adherence to the "federated strike" normative appeal will follow the ascending continuum: use-coercive-prescription-legitimate.

\subsubsection{Method}

\subsubsection{Participants}

Three hundred four students participated in the study $\left(M_{\text {age }}=21.83 ; S D=2.39\right) ; 145$ were female $\left(M_{\text {age }}=21.59\right.$; $S D=2.00), 151$ were male $\left(M_{\text {age }}=22.07 ; S D=2.71\right)$ and seven did not provide this information. 84 subjects studied Dentistry, 76 Law, 77 Psychology and 67 Civil Engineering.

\subsubsection{Construct measurements}

Normative Evaluation Scale (EMNA). This instrument (see the APPENDIX) contains a four-item scale to measure formality (e.g., "This appeal is formal"), and an eight-item scale to measure protection (e.g., "This appeal contributes to my personal well-being"). A 10-point Likert scale was used ( 1 = Minimum, $10=$ Maximum). Taking into account the size of the scales (Loewnthal, 1996; Nunally, 1995), the Cronbach's alpha internal consistency index showed an acceptable level on both scales (.68 and .83 for formality and protection, respectively).

Adherence to the normative appeal. We consider that by asking directly about the willingness to comply the answers could be biased by social desirability. To mitigate this effect, we asked participants to report their degree of "agreement" with the appeal on a 10-point Likert scale $(1=$ Totally disagree, $10=$ Totally agree $)$. 


\subsubsection{Procedure}

The participants completed the instrument in their classrooms. Before beginning the study, the aim was explained to the students and they were told that participation was completely anonymous and voluntary, and it entailed no physical or psychological risks. Next, the participants read and signed an informed consent form. The questionnaire was then handed out and answered on an individual basis.

The questionnaire design followed the standard procedure used in appraisal studies (Scherer, 2001). Students were first told: "Focus on the role you play in the organization and assess the following action appeal." Next, the appeal "The federated strike must be respected" was presented and the participant was asked to answer the twelve items measuring the two dimensions proposed by the model (i.e., formality and protection) and then the measurement of adherence to the appeal. After approximately half an hour, the material was collected and the students were asked about any possible doubts or difficulties they might have had. The participants did not report any problems that would invalidate their participation. Finally, they were thanked for their participation in the study. The participants did not receive any type of compensation in exchange for their participation. Finally, it should be pointed out that the questionnaire included other measures related to the perception of the norms that were not included in the present work, as they form part of a complementary line of research.

\subsubsection{Results}

To analyze whether the level of adherence to the appeal follows the continuum that goes from use, to coercive, to prescription, to legitimate; we first calculate the average of the items to form the formality and protection variables. Next, the scores for these variables were dichotomized into "high" when they were above the mean and "low" when they were below the mean $\left(M_{\text {formality }}=5.13 ; M_{\text {protection }}=5.33\right)$. The dichotomized measures of protection (high/low) and formality (high/low) were combined in an ordinal variable that represents the EMNA categories: 1 = use (low protection and low formality), $2=$ coercive (low protection and high formality), $3=$ prescription (high protection and low formality) and $4=$ legitimate (high protection and high formality). Using this combined ordinal variable, a one-factor ANOVA analysis was performed to check whether the four model categories are related to the level of adherence, in line with the hypothesis. Before beginning this analysis, the normality and homoscedasticity assumptions were checked. The asymmetry and kurtosis values of the dependent variable fell within the range -2 to +2 for the four categories of the independent variable, which made it possible not to reject the assumption of normality (George \& Mallery, 2010). While Levene's test led us to reject the equality of variances (Levene $[3,297]=3.896 ; p=.009$ ), the ANOVA test is considered robust for violations of this case, especially when the $\mathrm{N}$ of the groups are relatively homogeneous and the samples are not small (Ito, 1980), as in this case. In any case, the Welch statistic, recommended in the case of heteroscedasticity of variances, confirms the significance of the $\mathrm{F}$ test (Welch $[3,297]=39.68 ; p<.01$ ).

The results of the ANOVA test revealed a significant effect of the EMNA categories on adherence $(F[3,297]=$ $\left.36.53 ; p<.01 ; \eta^{2}=.27\right)$ and the weighted linear contrast confirmed that the means of the four categories follow the hypothesized continuum $(F[1,297]=103.88 ; p<.001 ; M s=3.89,4.51,6.92$ and 7.89 for use, coercive, prescription and legitimate, respectively) and the DMS post-hoc test showed that the means of all the categories were significantly different from one another $(p<.05)$, with the sole exception for the use vs. coercive difference.

In addition, the Pearson correlations of perceived formality and protection (not dichotomized) with the agreement with the normative appeal were positive and significant in both cases, although in line with what was proposed by the model, the correlation with protection was more intense than the correlation with formality ( $r s$ $=.67$ and $.19 ;$ s $<.05$, respectively).

\subsubsection{Discussion}

In a real context that involved university students, the results of this study showed that the level of adherence to a specific normative appeal followed a pattern consistent with the ascending continuum proposed by the EMNA: use-coercive-prescription-legitimate. In the second study, we conduct the same analysis in an also real but different context: employees in organizations of the public sector. 


\subsection{Study 2}

The aim of the present study was to further test the predictive validity of the EMNA in the public labor organization context. We conducted the design of Study 1 with a different sample (employees of public organizations) to assess two normative appeals that are typical in this context: "Comply with the entry and exit schedules" and "Not using the Internet for personal reasons". We again hypothesized that the level of adherence to each appeal will depend on how they are perceived according to the two-dimensional normative appraisal. Specifically, the adherence will follow the legitimate-prescription-coercive-use continuum.

\subsubsection{Method}

\subsubsection{Participants}

296 employees of four public organizations (Institution $1=100$; Institution $2=27$; Institution $3=66$; Institution $4=100$; and three participants who left out this information) participated in the study $\left(M_{\text {age }}=42.49\right.$; $S D=12.17) ; 147$ were female $\left(M_{\text {age }}=41.20 ; S D=11.70\right), 144$ were male $\left(M_{\text {age }}=43.83 ; S D=12.53\right)$ and five participants did not provide this information.

\subsubsection{Construct measurements}

Normative Evaluation Scale (EMNA). The same instrument presented in Study 1 (see the APPENDIX) was used, which measures the dimensions of formality (4 items) and protection (8 items), using a 10-point Likert scale $(1=$ Minimum, $10=$ Maximum $)$. The internal consistency index showed adequate levels for both scales $(.73$ $<$ as $<.80)$.

Adherence to the normative appeal. The level of adherence was measured, following the same procedure as in Study 1. Accordingly, the participants indicated on a 10-point Likert scale the extent to which they agreed with the following normative appeals: "Comply with the entry and exit schedules" and "Not using the Internet for personal reasons."

\subsubsection{Procedure}

The participants were contacted individually at their workplace, with prior authorization from the organization. Schedules were adapted to the availability of each employee. Before beginning the study, the aim was explained to the participants and they were told that participation was completely anonymous and voluntary, and it entailed no physical or psychological risks. Next, the participants read and signed an informed consent form. The questionnaire was then handed out and answered on an individual basis.

Like in Study 1, the questionnaire design followed the standard procedure used in appraisal studies (Scherer, 2001). Therefore, the participant completed the instrument that measures the perceived level of formality and protection, and degree of adherence, for each of the two normative appeals. After approximately half an hour, the material was collected, and the students were asked about any possible doubts or difficulties they might have had. The participants did not report any problems that would invalidate their participation. Finally, they were thanked for their participation in the study. The participants did not receive any type of compensation in exchange for their participation. The questionnaire included other measures related to the perception of the normative appeals that were not included in the present work, as they form part of a complementary line of research.

\subsubsection{Results}

To analyze whether the level of adherence is related to the model categories on an ascending continuum that goes from use to coercive to prescription to legitimate, we first introduced the formality and protection variables based on the aggregated sum of their items. 
Next, these variables were dichotomized based on their mean $M \mathrm{ss}_{\text {protection }}=7.55$ and $5.84 ; M \mathrm{sf}_{\text {ormality }}=7.36$ and 5.58 , for the normative appeals "Comply with the entry and exit schedules" and "Not using the Internet for personal reasons," respectively), determining the four normative categories, and the pattern of the level of adherence was analyzed, following the procedure described in Study 1. Regarding the assumptions of normality and homoscedasticity, the asymmetry and kurtosis values of the dependent variable were shown within the range -2 and +2 , in the four categories of the EMNA for both normative appeals. Regarding homoscedasticity, the Levene statistic was significant for both normative appeals $(p s<.05)$. Taking into account that the Welch statistic confirmed the significance of the F test in both cases $(p s<.01)$, and that the ANOVA test is robust under these conditions, we proceeded with the main analyzes.

For the appeal "Comply with the entry and exit schedules" the analysis revealed a significant effect of the EMNA categories on adherence $\left(F[3,267]=12.10 ; p<.01 ; \eta^{2}=.12\right)$ and the weighted linear contrast confirmed that the means of each category follow the hypothesized continuum $(F[1,267]=33.16 ; p<.001 ; M \mathrm{~s}=7.85$, 8.65, 9.40 and 9.49 for use, coercive, prescription and legitimate, respectively). Moreover, the DMS post-hoc test showed that the means of all the categories were significantly different from one another $(p<.05)$, with the sole exception of the prescription vs. legitimate difference. In addition, protection was positively and significantly related to the level of adherence $(r=.44, p<.05)$, but in this case formality showed no significant relationship $(r$ $=.08$ ). In general, for this normative appeal the results partially supported the premises of the model.

For the appeal "Not using the Internet for personal reasons," the analysis revealed a significant effect of the categories of the EMNA variable on adherence $\left(F[3,278]=21.10 ; p<.01 ; \eta^{2}=.19\right)$ and the weighted linear contrast confirmed that the means of each category follow the hypothesized continuum $(F[1,278]=60.14 ; p$ $<.001, M \mathrm{~s}=4.20,5.74,7.31$ and 7.63 for use, coercive, prescription and legitimate, respectively). Furthermore, the DMS post-hoc test showed that the means of all the categories were significantly different from one another $(p<.05)$, with the sole exception of the prescription vs. legitimate difference. When the non-dichotomized measures of protection and formality were analyzed separately, we found that both were positively and significantly related to the level of adherence to the normative appeal, and in line with the model, the relationship to protection was stronger than the relationship to formality ( $r s=.52$ and .23 ; $p$ s $<.05$, respectively).

\subsubsection{Discussion}

The results of this second study reinforce the previous findings that support the premises of the EMNA in a labor organization context, which evidences its potential as a diagnostic tool on the perception of normative appeals. Specifically, with regard to the perception of the two widely used normative appeals in the organizational setting, the results showed that the four categories derived from the EMNA appraisal were related to different levels of adherence in line with the hypothesized continuum use-coercive-prescription-legitimate. Probably due to a ceiling effect (i.e., all the participants showed a very high level of adherence to the appeal regarding the observance of timetables), the results more clearly supported the pattern as compared to the appeal concerning inappropriate Internet use.

\section{General discussion}

This work analyzed the basic premises of the EMNA, complementing the findings described in the previous literature and backing their potential as a normative diagnostic tool in an organizational setting. Even though Oceja et al. (2016) already presented evidence supporting the two fundamental premises of the EMNA, this work complements the previous research in at least three aspects. First of all, in the previous research, the relationship between the normative categories of the EMNA and the level of adherence were analyzed on the inter-subject level, in such a way that the level of adherence could have been largely due to certain objective characteristics of the normative appeal (e.g., visibility of the proposed action) and, to a lesser extent, to the subjective process of perception of said appeal in terms of formality and protection (i.e., normative appraisal). On the other hand, the results of the present work show that different people not only perceive the same normative appeal differently, they show a coherent level of adherence to the premises of the EMNA. 
Secondly, Oceja et al. (2016) operationalized formality and protection with measures of only one item, which can lead to problems related to the precision and stability of the measurement (Nunnally \& Bernstein, 1995; Venkatraman \& Grant, 1986). In the present work, this limitation was dealt with by using scales made up of several items that generally showed adequate levels of internal consistency and predictive validity. Finally, in the present work, the EMNA was applied to analyze the perception of real normative appeals in two different organizational contexts.

\section{Conclusions}

Several previous works approached the analysis of different compliance antecedents, comparing the strategies based on intrinsic and extrinsic motivators. Hofeditz Nienaber, Dysvik and Schewe (2017) considered this duality as the "want to" vs. the "have to" effect. Paine (1994) proposed that the two main strategies for managing compliance are the legal one (extrinsic) and integrity (intrinsic). Weaver and Treviño (2001) compared compliance orientation (extrinsic) to value orientation (intrinsic). Stansburry and Barry (2007) made the distinction between enabling control (intrinsic) and coercive control (extrinsic). Tyler and Blader (2005) compared the effect of the strategy based on master and control (extrinsic) with the strategy based on selfregulation (intrinsic). The recurring conclusion in this research (e.g., Hofeditz et al., 2017; Tyler \& Blader, 2005) is that the strategies based in intrinsic motivation are more effective in terms of achieving adherence than those based on extrinsic motivation. In this line, the results of the two studies showed that the adherence was more related to the perceived protection than to the perceived formality. Since the EMNA proposes that the dimension of protection is related to the self-regulatory system (Higgins, 2012), one could argue that focusing on either the perceived protection or formality can be depicted as an "intrinsic" or "extrinsic" strategy, respectively. The relative effectiveness of these two strategies could be examined by further research conducted under the perspective provided by the EMNA.

Specifically, the work presented here complements this knowledge in at least two aspects. On the one hand, the EMNA considers that the initial process of perception of a normative appeal (normative appraisal) is structured around two dimensions, one with a greater extrinsic character (formality) and another with a greater intrinsic character (protection). In other words, the degree of association of a normative appeal to a formal institution is a characteristic perceived by, but independent from the person paying attention; on the other hand, the degree to which the normative appeal maintains security and autonomy is not only perceived by, but also depends to a great extent on the characteristics of the affected person.

Previous research has focused on understanding and comparing the effect of certain global forms of normative management (intrinsic and extrinsic) on the general willingness to comply. Using the EMNA to diagnose implies focusing on the analysis of the normative appraisals that arise from one or more specific appeals, which would allow reaching a more precise diagnosis of their perception and the willingness to comply associated. Our work can be combined with prior research on normative compliance in at least two aspects. Firstly, the EMNA considers that the evaluation of a normative appeal is organized around an extrinsic variable (perceived formality) and an intrinsic variable (perceived protection) which, while they can be analyzed separately, form part of a primary and complementary normative assessment (i.e., normative appraisal). Secondly, the previous research focused on the comparison of (intrinsic vs. extrinsic) management strategies did not assess the impact of specific normative appeals. Therefore, the procedure and measures used in the present work could diagnose with greater precision the effectiveness of different strategies on increasing the adherence to an organizational coded formed by a set of normative appeals.

In summary, from an applied perspective, the analysis of the normative appraisal proposed by the EMNA may assist normative management on two fronts. First, by predicting the adherence to a normative code formed by specific appeals, and second, by monitoring the effectiveness of an intervention designed to influence on how a specific appeal is perceived. Furthermore, the interest in applying the EMNA may be greater if it is taken into account that the management of norms focused on increasing the level of adherence is usually approached almost exclusively through increases in the levels of control and sanctions, factors that by themselves are insufficient to improve the levels of compliance, while at the same time they commit an important amount of 
human and financial resources (Tyler \& Blader, 2005). In other words, the EMNA premises offer a parsimonious solution with great potential to make a primary diagnosis that guides the decision-making process in designing and implementing normative management tactics (Foorthuis, 2012).

With respect to the tactics that can be adopted based on the diagnosis, these would be aimed at increasing the perception of protection among those who are perceiving an important organizational regulation as use or coercive or aimed at increasing the perception of formality among those who are perceiving it as use or prescription. In addition, the results obtained after a diagnosis based on the EMNA can orient new studies that allow us to delve deeper into the causes of the levels of formality and/or perceived protection that prove inadequate from the perspective of the organization. The study of these causes would enable us to improve the design of new intervention actions, as well as determine good normative management practices among those groups who have perceived the normative appeal in accordance with the interest of the organization.

\subsection{Limitations and future research}

Within the challenge of diagnosing the perception of the normative appeals, the EMNA is complemented by other explanatory models. Therefore, along with an analysis of the normative appraisal (perception of formality and protection), it would be relevant to measure the level of value-related affinity between what is expressed by the appeal and the personal values (see the person-organization fit by Edwards \& Cable, 2009), the legitimacy of the authority from which the normative appeal emanates (see the Relational Model of Authority by Tyler, 2006; Tyler \& Lind, 1992), the descriptive and injunctive quality of the appeal (see the Focus Theory of Normative Conduct by Cialdini et al., 1990; Cialdini et al., 1991), and the perception of the degree of severity and certainty of sanction (e.g., Becker, 2004), among others. The more comprehensive inclusion of these variables the stronger development of strategies that anticipates and, if possible, increase the levels of adherence to the norms that regulate the smooth operation of social and organizational contexts. In addition, another pending topic is to replicate these results and analyze the validity of the scales in new samples in different countries and cultures.

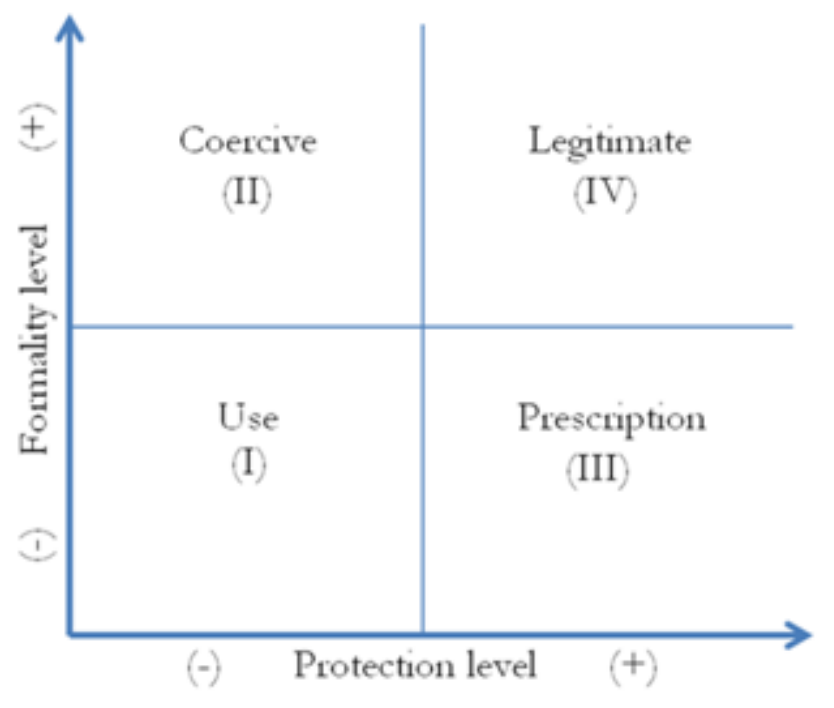

Figure 1. The Evaluative Model of Normative Appeals (EMNA).

Parentheses show the ascending continuum of willingness to comply associated with each of the model categories. 


\section{Declaration of Conflicting Interests}

The authors declared no potential conflicts of interest with respect to the research, authorship, and/or publication of this article.

\section{Funding}

This work has been supported mainly by the "Programa CONICYT, FONDECYT Iniciación 11130710 (Chile)"; and to a lesser extent, by the "Universidad de La Frontera, Proyecto DIUFRO DI15-0056"; and by the "Convenio de Desempeño Regional, FRO 1301".

\section{References}

Abad, F.J., Olea, J., Ponsoda, V., \& García, C. (2011). Medición en ciencias sociales y de la salud. Madrid, Síntesis.

Andenaes, J. (1974). Punishment and deterrence. University of Michigan Press.

Beccaria, C. (1764/2011). De los delitos y de las penas. México: Fondo de Cultura Económica.

Beramendi, M., Salgado, S., \& Oceja, L. (2018). Validation of an instrument to assess the perception of normative appeals: A measure inspired on the EMMA model. Unpublished manuscript.

Becker, G.S. (2004). Crime and Punishment: An Economic Approach. In D.A. Wittman (Ed.), Economic Analysis of the Law: Selected Readings (pp. 255-265). Oxford, UK.: Blackwell Publishing Ltd.

https://doi.org/10.1002/9780470752135.ch25

Boda, Z., \& Zsolnai, L. (2016). The failure of business ethics. Society and Business Review, 11, 93-104. https://doi.org/10.1108/SBR-11-2015-0066

Burke, R.J., \& Cooper, C.L. (2009). Research companion to corruption in organizations. Chichester: Edward Elgar Publishing. https://doi.org/10.4337/9781849801928

Cheng, L., Li, W., Zhai, Q., \& Smyth, R. (2014). Understanding personal use of the Internet at work: An integrated model of neutralization techniques and general deterrence theory. Computers in Human Behavior, 38, 220-228. https://doi.org/10.1016/j.chb.2014.05.043

Cheng, L., Li, Y., Li, W., Holm, E., \& Zhai, Q. (2013). Understanding the violation of IS security policy in organizations: An integrated model based on social control and deterrence theory. Computers \& Security, 39, 447-459. https://doi.org/10.1016/j.cose.2013.09.009

Cialdini, R.B. (2012). The focus theory of normative conduct. In P.A.M. Van Lange, A.W. Kruglanski \& E.T. Higgins (Eds.), Handbook of theories of social psychology (Vol. 2, pp. 295-312). Thousand Oaks, CA: Sage. https://doi.org/10.4135/9781446249222.n41

Cialdini, R.B., \& Goldstein, N.J. (2004). Social Influence: Compliance and Conformity. Annual Review of Psychology, 55, 591-621. https://doi.org/10.1146/annurev.psych.55.090902.142015

Cialdini, R.B., Kallgren, C.A., \& Reno, R.R. (1991). A focus theory of normative conduct: A theoretical refinement and reevaluation of the role of norms in human behavior. Advances in Experimental Social Psychology, 24, 201-234. https://doi.org/10.1016/S0065-2601(08)60330-5

Cialdini, R.B., Reno, R.R., \& Kallgren, C.A. (1990). A focus theory of normative conduct: Recycling the concept of norms to reduce littering in public places. Journal of Personality and Social Psychology, 58, 1015-1026. https://doi.org/10.1037/0022-3514.58.6.1015

Cornish, D., \& Clarke, R. (2013). The reasoning criminal: Rational choice perspectives on offending. Piscataway: Transaction Publishers.

Detert, J.R., Treviño, L.K., Burris, E.R., \& Andiappan, M. (2007). Managerial modes of influence and counterproductivity in organizations: A longitudinal business-unit-level investigation. Journal of Applied Psychology, 92, 993-1005. https://doi.org/10.1037/0021-9010.92.4.993 
Dowling, J., \& Pfeffer, J. (1975). Organizational legitimacy: Social values and organizational behavior. Pacific sociological review, 18, 122-136. https://doi.org/10.2307/1388226

Edwards, J.R., \& Cable, D.M. (2009). The value of value congruence. Journal of Applied Psychology, 94, 654-677. https://doi.org/10.1037/a0014891

Fabrigar, L.R., Wegener, D.T., MacCallum, R.C., \& Strahan, E J. (1999). Evaluating the use of exploratory factor analysis in psychological research. Psychological Methods, 4(3), 272-299. https://doi.org/10.1037/1082-989X.4.3.272

Foorthuis, R.M. (2012). Tactics for Internal Compliance: A Literature Review. In Project Compliance with Enterprise Architecture (pp. 153-198), Doctoral dissertation (PhD thesis), Utrecht University, Center for Organization and Information. ISBN: 978-90-393-5834-4.

George, D., \& Mallery, M. (2010). Using SPSS for Windows step by step: a simple guide and reference. Boston, MA: Allyn \& Bacon.

Greve, H.R., Palmer, D., \& Pozner, J.E. (2010). Organizations gone wild: The causes, processes, and consequences of organizational misconduct. Academy of Management Annals, 4, 53-107. https://doi.org/10.1080/19416521003654186

Harkins, S.G., Williams, K.D., \& Burger, J.M. (2017). The Oxford handbook of social influence. Oxford University Press.

Healy, M., \& Iles, J. (2002). The establishment and enforcement of codes. Journal of Business Ethics, 39, 117-124. https://doi.org/10.1023/A:1016392203507

Higgins, E.T. (2012). Beyond pleasure and pain: How motivation works. New York, NY: Oxford University Press.

Hofeditz, M., Nienaber, A.M., Dysvik, A., \& Schewe, G. (2017). "Want to" Versus "Have to": Intrinsic and Extrinsic Motivators as Predictors of Compliance Behavior Intention. Human Resource Management, 56, 25-49. https://doi.org/10.1002/hrm.21774

Ito, P.K. (1980). Robustness of ANOVA and MANOVA test procedures. In P.R. Krishnaiah (Ed.), Handbook of statistics 1. Analysis of variance (pp. 199-236). Amsterdam: North Holland. https://doi.org/10.1016/S01697161(80)01009-7

Kallgren, C.A., Reno, R.R., \& Cialdini, R.B. (2000). A focus theory of normative conduct: When norms do and do not affect behavior. Personality and Social Psychology Bulletin, 26, 1002-1012.

https://doi.org/10.1177/01461672002610009

Katyal, N. (1997). Deterrence's difficulty. Michigan Law Review, 95, 2385-2476. https://doi.org/10.2307/1290124

Llinares, F.M., \& Ortuño, R.B. (2013). ¿Por qué cumplimos las normas penales? Sobre la disuasión en materia de seguridad vial. InDret, (4). Retrieved from: www.indret.com/pdf/1001.pdf

Loewnthal, K.M. (1996). An introduction to psychological tests and scales. London: UCL Press.

MacCoun, R.J. (1993). Drugs and the law: A psychological analysis of drug prohibition. Psychological bulletin, 113, 497-512. https://doi.org/10.1037/0033-2909.113.3.497

Markell, D.L. (2000). The role of deterrence-based enforcement in a "reinvented" state/federal relationship. Harvard Environmental Law Review, 24, 1-114. https://ssrn.com/abstract=1547897

Morris, M.W., Hong, Y., Chiu, C., \& Liu, Z. (2015). Normology: Integrating insights about social norms to understand cultural dynamics. Organizational Behavior and Human Decision Processes, 129, 1-13.

https://doi.org/10.1016/j.obhdp.2015.03.001

Nagin, D., \& Paternoster, R. (1991). The preventive effects of the perceived risk of arrest. Criminology, 29, 561-585. https://doi.org/10.1111/j.1745-9125.1991.tb01080.x

Nunnally, J.C., \& Bernstein, I. (1995). Teoría psicométrica (3rd Ed.). México: McGraw-Hill. 
Oceja, L., Villegas, M., Beramendi, M., \& Salgado, S. (2016). "You should (not) do that": An Evaluative Model of Normative Appeals (EMNA). The Journal of social psychology, 156, 382-396.

https://doi.org/10.1080/00224545.2015.1111855

Paine, L. (1994). Managing for organizational integrity. Harvard Business Review, 72, 106-117.Retrieved from: https://hbr.org/1994/03/managing-for-organizational-integrity

Paternoster, R., \& Bachman, R. (2013). Perceptual deterrence theory. In F. Cullen and P. Wilcox (Eds.), The Oxford handbook of criminological theory (pp. 649-671). https://doi.org/10.1093/oxfordhb/9780199747238.013.0033

Pfeffer, J. (1981). Management as symbolic action: The creation and maintenance of organizational paradigms. In L. L. Cummings \& B. M. Staw (Eds.), Research in organizational behavior (The role of deterrence-based enforcement in a "reinvented" state/federal relationship (Vol. 13, pp. 1-52). Greenwich, CT: JAI Press.

Pfeffer, J., \& Salancik, G. (1978). The external control of organizations: A resource dependence perspective. New York: Harper \& Row.

Reno, R.R., Cialdini, R.B., \& Kallgren, C.A. (1993). The transsituational influence of social norms. Journal of Personality and Social Psychology, 64, 104-112. https://doi.org/10.1037/0022-3514.64.1.104

Salgado, S., Casagrande, J., González-Suhr, C., Oceja, L., \& Beramendi, M. (2014). Construcción y pilotaje de tres instrumentos de medida de la percepción de las normas en el ámbito organizacional. Proceedings of the $2^{\circ}$ Congreso Chileno de Psicología Organizacional y del Trabajo, Santiago, Chile.

Scherer, K.R. (2001). Appraisal considered as a process of multi-level sequential checking. In K. R. Scherer, A. Schorr \& T. Johnstone (Eds.), Appraisal processes in emotion: Theory, methods, research (pp. 92-120). New York, NY: Oxford University Press.

Son, J.Y. (2011). Out of fear or desire? Toward a better understanding of employees' motivation to follow IS security policies. Information \& Management, 48, 296-302. https://doi.org/10.1016/j.im.2011.07.002

Stansburry, J., \& Barry, B. (2007). Ethics managements and the paradox of control. Business Ethics Quarterly, 17, 239-261. https://doi.org/10.5840/beq200717229

Suchman, M.C. (1995). Managing legitimacy: Strategic and institutional approaches. Academy of management review, 20, 571-610. https://doi.org/10.5465/amr.1995.9508080331

Sutinen, J.G., \& Kuperan, K. (1999). A socioeconomic theory of regulatory compliance. International Journal of Social Economics, 26, 174-193. https://doi.org/10.1108/03068299910229569

Tyler, T.R. (2006). Psychological perspectives on legitimacy and legitimation. Annual Review of Psychology, 57, 375-400. https://doi.org/10.1146/annurev.psych.57.102904.190038

Tyler, T.R., \& Blader, S.L. (2000). Cooperation in groups: Procedural justice, social identity, and behavioral engagement. Philadelphia: Psychology Press.

Tyler, T.R., \& Blader, S.L. (2005). Can businesses effectively regulate employee conduct? The antecedents of rule following in work settings. Academy of Management Journal, 48, 1143-1158.

https://doi.org/10.5465/amj.2005.19573114

Tyler, T.R., \& Lind, E.A. (1992). A relational model of authority in groups. Advances in experimental social psychology, 25, 115-191. https://doi.org/10.1016/S0065-2601(08)60283-X

Tyler, T.R., \& Huo, Y. (2002). Trust in the law: Encouraging public cooperation with the police and courts through. New York: Russell Sage Foundation.

Venkatraman, N., \& Grant, J.H. (1986). Construct measurement in organizational strategy research: A critique and proposal. Academy of management review, 11, 71-87. https://doi.org/10.5465/amr.1986.4282628

Verplanken, B., \& Holland, R.W. (2002). Motivated decision making: Effects of activation and self-centrality of values on choices and behavior. Journal of Personality and Social Psychology, 82, 434-447.

https://doi.org/10.1037/0022-3514.82.3.434 
Weaver, G.R., \& Treviño, L.K. (2001). Outcomes of organizational ethics managements: Influences of perceived values, compliance, and distrust orientations. Academy of Management Proceedings, 1, B1-B6. https://doi.org/10.5465/APBPP.2001.6133849

West, S.G., Finch, J.F., \& Curran, P.J. (1995). Structural equation models with nonnormal variables. Problems and remedies. In R.H. Hoyle (Ed.), Structural equation modelling: Concepts, issues and applications (pp. 56-75). Newbury Park, CA: Sage.

\section{Appendix I}

Normative Evaluation Scale (EMNA). The instrument consists of two scales (see Table 1). The formality scale (i.e., degree to which the person perceives that the appeal comes from a formal institution that backs it and strives to ensure its compliance); and the protection scale (i.e., degree to which the person perceives that the proposal prevents harm to him/her and promotes the performance of the action). On the protection scale, the items indicated "(I)" are written in the opposite sense of the definition and are focused on the idea of the performance of the action, while the other four items are focused on the idea of protecting against harm.

\begin{tabular}{|l|}
\hline \multicolumn{1}{|c|}{ Formality } \\
\hline When this appeal is violated, it is sanctioned \\
\hline This appeal is formal \\
\hline This appeal is applied with authority \\
\hline Compliance is demanded with this appeal \\
\hline \\
\hline This appeal affects my private life (I) \\
\hline This appeal takes freedom or autonomy away from me (I) \\
\hline This appeal restricts me as a person (I) \\
\hline This norm complicates my comprehensive development $(\mathrm{I})$ \\
\hline This appeal contributes to my personal well-being \\
\hline This appeal looks after me and my interests \\
\hline This appeal looks after my rights as a person \\
\hline This appeal helps me in what I consider to be important \\
\hline
\end{tabular}

Table 1. The EMNA instrument

Analysis of the instrument. Before exploring the empirical structure of the instrument, the adequacy of the data to the exploratory factorial analysis was analyzed. The KMO test and Bartlett's Sphericity test showed adequate levels for the data in Study 1 ("The federated strike must be respected"; $p>.84$ and $p<.01$, respectively) and in Study 2 ("Comply with the entry and exit schedules"; $p>.78$ and $p<.01$, respectively; and "Not using the Internet for personal purposes"; $p>.80$ and $p<.01$, respectively). The Kolmogorov-Smirnov test, in turn, showed scores that in general do not fit the normal distribution $(p \mathrm{~s}>.05)$. However, the asymmetry and kurtosis values showed acceptable levels, within the -2 to +2 range, except for the item "This appeal is formal," which showed an asymmetry of 2.31 with the proposal "Comply with the entry and exit schedules." It is estimated that these values are adequate to proceed with an AFE (Abad, Olea, Ponsoda \& García, 2011; West, Finish \& Curran, 1995). In any case, the Principal Axis extraction method was used, which is the classic recommendation when the normality assumption is not met (Fabrigar, Wegener, MacCallum \& Strahan, 1999), with Oblimin rotation with Kaiser. Table 1 shows the scale items. The result of the three AFEs revealed a three-factor solution that fits the definitions of the model, which altogether explained between $63.64 \%$ and $68.16 \%$ of the variance: one factor on which all the formality items saturated with weights above .41, which explained between $11.85 \%$ and $22.6 \%$ of the variance, and two factors on which the protection items saturated (one on which the four items related to preventing harm saturated with weights greater than .73 and another on which the four items related to the performance of the action saturated with weights greater than .61). These factors individually explained between $8.99 \%$ and $32.66 \%$ of the variance. The only exception to this structure corresponds to the item "This proposal is formal," which in Study 1, in addition to saturating in its dimension (.41), also saturated along with the protection from harm items (.54). These results are coherent with the pilot study of the instrument (Salgado, Casagrande, González-Suhr, Oceja \& Beramendi, 2014) and with a validation work done after the studies presented here $(\mathrm{N}=2376$; from eight countries; Beramendi, Salgado \& Oceja, 2018). In this latest work, it was verified that the instrument fits the two- dimension model (formality and protection) through a confirmatory 
second-order analysis, where protection is represented in turn by two sub-dimensions consisting of the results described above. In this sense, it is important to indicate that the correlations between the protection factors obtained in this work $(r s>.13$ and $<.38)$ neither support nor rule out the existence of a sole underlying variable; however, their processing as a single-dimension scale is appropriate, considering the theoretical definition of the model, the levels of internal consistency obtained and the result of the validation study (Beramendi et al., 2018).

Intangible Capital, 2018 (www.intangiblecapital.org)

\section{(c) (1) (\$)}

Article's contents are provided on an Attribution-Non Commercial 4.0 Creative commons International License. Readers are allowed to copy, distribute and communicate article's contents, provided the author's and Intangible Capital's names are included. It must not be used for commercial purposes. To see the complete license contents, please visit https://creativecommons.org/licenses/by-nc/4.0/. 